\title{
Determination of Growth Performance, Viscera Organ Weights and Ileal Intestinal Architecture of Broilers in Response to Drinking Water Added Extractions from Wooden Chips for the Starter Period
}

\author{
Shemil Priyan Macelline, ${ }^{1, *}$, Samiru Sudharaka Wickramasuriya ${ }^{1, *}$, Taeg Kyun Shin ${ }^{1}$, Eunjoo Kim ${ }^{1}$, \\ Hyun Min Cho', Jun Seon Hong', Jeong Bin $\mathrm{Nam}^{2}$, Seung Min Yang ${ }^{3}$, Geun Hye $\mathrm{Oh}^{3}$, \\ Seog Goo $\mathrm{Kang}^{4}$ and Jung Min $\mathrm{Heo}^{5,}$ \\ ${ }^{1}$ Student, Department of Animal Science and Biotechnology, Chungnam National University, Daejeon 34134, Republic of Korea \\ ${ }^{2}$ Research Professor, Department of Bio-Based Materials, Chungnam National University, Daejeon 34134, Republic of Korea \\ ${ }^{3}$ Student, Department of Bio-Based Materials, Chungnam National University, Daejeon 34134, Republic of Korea \\ ${ }^{4}$ Professor, Department of Bio-Based Materials, Chungnam National University, Daejeon 34134, Republic of Korea \\ ${ }^{5}$ Professor, Department of Animal Science and Biotechnology, Chungnam National University, Daejeon 34134, Republic of Korea
}

\begin{abstract}
A total of 90 one-day-old male broilers (Ross 308) were randomly assigned to one of the three dietary treatments, each consisting of six replicates ( 5 broilers/cage). The dietary treatments were 1$)$ control (CON: fresh clean water with no supplement); 2) low dose [LD: CON $+1.56 \%$ extractions from the wooden chips (EWC)] and 3) high dose (HD: CON $+12.5 \%$ EWC). Drinking water supplemented with EWC was provided using specifically designed individual nipple drinker units. Average daily water intake (ADWI), average daily gain (ADG), average daily feed intake (ADFI), and feed conversion ratio (FCR) were measured weekly for 21 days. One broiler from each cage was euthanized for measuring the visceral organ weights and collecting ileal tissue samples for ileal architecture analysis on day 21 . Broilers assigned to the LD and HD watery groups showed higher ADWI than that in broilers consumed CON on day $7(P<0.05)$. The broilers subjected to HD treatment showed a deeper crypt depth $(P<0.05)$ than that in broilers subjected to LD and CON on day 21 . Therefore, broilers consumed HD showed a lower $(P<0.05)$ villus height:crypt depth ratio than that broilers consumed CON on day 21. Broilers provided drinking water containing any of the tested concentrations of EWC showed no effect $(P>0.05)$ on growth performance, ileal villus height, and visceral organ weights as compared with those in the CON from hatch to 21 days. In conclusion, broilers fed HD showed reduction in villus height:crypt depth ratio without impairing growth performance and visceral organ weights for the experimental period.
\end{abstract}

(Key words: extractions from the wooden chips, growth performance, viscera organ weights, water intake)

\section{INTRODUCTION}

Many studies with respect to therapeutic or sub therapeutic use of antibiotic improved growth performance but decreased mortality and morbidity in production animals (Doyle, 2001). However, critical anxiety raised about transmitting bacterial antibiotic resistance in humans and discharge of antimicrobial compounds (i.e., zinc, copper) to the environment (Ogawara, 1981; Russell, 1991; Han, 2007). In this regard, much interests in alternatives/replacements for dietary antimicrobial products are increasing in poultry production (Patterson and Burkholder, 2003; Niewold, 2007).

\footnotetext{
${ }^{*}$ These authors have contributed equally to this work.

${ }^{\dagger}$ To whom correspondence should be addressed : jmheo@cnu.ac.kr
}

There are many different kind of plant extract (barley, whole grains, oak, etc.) which affects antioxidant capacity depending on the amounts of polychemicals (Duh et al., 2001; Liu, 2007; Mateo et al., 2009; Num et al., 2017). However, many antioxidative phenolic compounds in plants are predominantly present in a covalently bound form with an insoluble polymer (Gong et al., 2012). Therefore, it is necessary to find an effective processing method to release these compounds. Several methods including heat treatment (steam explosion and torrefaction), far-infrared (FIR) radiation, and enzymatic treatment, have been studied in order to liberate and activate low-molecular-weight antioxidants from various plants (Ahajji 
et al., 2009). Heat treatment of wood at moderate temperatures $\left(200 \sim 250^{\circ} \mathrm{C}\right)$ under an inert atmosphere (to avoid oxidative degradation) leads to formation of torrefied or heat-treated wood (Ahajji et al., 2009). Antioxidative phenolic compounds can be present in raw materials or produced during the heat-treatment process (Avat, 1993; Ahajji et al., 2009).

The purpose of the present study was to determine the beneficial effect of organic acids and phenolic compounds present in the extracts from Oak wood chips on broiler (Ross 308) growth performance, ileal intestinal architecture and viscera organ weights from hatch to 21 days.

\section{MATERIAL AND METHODS}

Experiment procedures were investigated and approved by the Animal Ethics Committee of the Chungnam National University (CNU-00903).

\section{Housing and Managements}

This study was conducted in the research facility of the Chungnam National University of South Korea. Eighteen wire floor cages $\left(0.85 \times 0.55 \times 0.35 \mathrm{~m}^{3}\right)$ were used as experiment units. Each cage consisted with specifically design individual nipple drinker unit with two nipple drinkers and a metal through feeder. All the broilers were allowed to ad-libitum access of corn and soybean-meal diet (Table 1) formulated to meet the nutrition requirement of poultry (NRC, 1994) without incorporation of any antibiotic growth promoters. The ambient temperature was maintained at $30 \pm$ $1{ }^{\circ} \mathrm{C}$ from days 1 to 3 and then gradually decreased to $25 \pm 1^{\circ} \mathrm{C}$ and it was maintained until the end of the experiment.

\section{Preparation of Extractions from Wooden Chips}

Torrefaction of the oak wooden chips was achieved using a laboratory scale reactor as described by Nam et al. (2018). A prescribed amount of oak wooden chips was weighed and placed in the center of the reactor. An external dryer was used to dry the chips to $<15 \%$ moisture prior to torrefaction. The wooden chips were torrefied at $240^{\circ} \mathrm{C}$ temperatures for $24 \mathrm{~h}$. After torrefaction, the material was ground and sieved to a maximum particle size of 60 mesh. The torrefied material
Table 1. Composition ( $\%$ as-fed basis) of the experimental diet

\begin{tabular}{|c|c|c|}
\hline \multicolumn{2}{|c|}{ Ingredients } & Amount \\
\hline \multicolumn{2}{|l|}{ Corn } & 45.08 \\
\hline \multicolumn{2}{|l|}{ Wheat } & 5.90 \\
\hline \multicolumn{2}{|l|}{ Wheat bran } & 6.22 \\
\hline \multicolumn{2}{|l|}{ Soybean meal $48 \%$} & 36.00 \\
\hline \multicolumn{2}{|l|}{ Vegetable oil } & 2.80 \\
\hline \multicolumn{2}{|l|}{ Limestone } & 1.50 \\
\hline \multicolumn{2}{|c|}{ Monocalcium phosphorus } & 1.70 \\
\hline \multicolumn{2}{|l|}{ Salt } & 0.30 \\
\hline \multicolumn{2}{|l|}{ Vit-min premix ${ }^{1}$} & 0.30 \\
\hline \multicolumn{2}{|l|}{ DL-methionine } & 0.20 \\
\hline \multirow{11}{*}{ Calculated values $^{2}$} & $\mathrm{ME}(\mathrm{kcal} / \mathrm{kg})$ & 3,200 \\
\hline & $\mathrm{CP}(\%)$ & 23 \\
\hline & NDF (\%) & 10.9 \\
\hline & $\mathrm{Ca}(\%)$ & 1.1 \\
\hline & Avail. P (\%) & 0.4 \\
\hline & Lys $(\%)$ & 1.3 \\
\hline & Met $(\%)$ & 0.5 \\
\hline & Met+Cys (\%) & 0.9 \\
\hline & Thr (\%) & 0.9 \\
\hline & $\operatorname{Trp}(\%)$ & 0.3 \\
\hline & Val (\%) & 1.1 \\
\hline
\end{tabular}

${ }^{1}$ Supplied per kilogram of total diets: $\mathrm{Fe}\left(\mathrm{FeSO}_{4} \cdot \mathrm{H}_{2} \mathrm{O}\right), 80 \mathrm{mg}$; $\mathrm{Zn}\left(\mathrm{ZnSO}_{4} \cdot \mathrm{H}_{2} \mathrm{O}\right), 80 \mathrm{mg} ; \mathrm{Mn}\left(\mathrm{MnSO}_{4} \cdot \mathrm{H}_{2} \mathrm{O}\right) 80 \mathrm{mg} ; \mathrm{Co}$ $\left(\mathrm{CoSO}_{4} \cdot \mathrm{H}_{2} \mathrm{O}\right) 0.5 \mathrm{mg} ; \mathrm{Cu}\left(\mathrm{CuSO}_{4} \cdot \mathrm{H}_{2} \mathrm{O}\right) 10 \mathrm{mg}$; $\mathrm{Se}\left(\mathrm{Na}_{2} \mathrm{SeO}_{3}\right)$ $0.2 \mathrm{mg} ; \mathrm{I},\left(\mathrm{Ca}\left(\mathrm{IO}_{3}\right) \cdot 2 \mathrm{H}_{2} \mathrm{O}\right) 0.9 \mathrm{mg}$; vitamin A, 24,000 IU; vitamin $\mathrm{D}_{3}, 6,000 \mathrm{IU}$; vitamin $\mathrm{E}, 30 \mathrm{IU}$; vitamin $\mathrm{K}, 4 \mathrm{mg}$; thiamin, $4 \mathrm{mg}$; riboflavin, $12 \mathrm{mg}$; pyridoxine, $4 \mathrm{mg}$; folacine, 2 $\mathrm{mg}$; biotin, $0.03 \mathrm{mg}$; vitamin $\mathrm{B}_{8}, 0.06 \mathrm{mg}$; niacin, $90 \mathrm{mg}$; pantothenic acid, $30 \mathrm{mg}$.

2 The values were calculated according to the values of feedstuffs in NRC (1994).

was stored in a desiccator at room temperature until chemical analyses. Extractions of torrefied wood were performed in bottles using water. Upon completion of extraction, the extract was filtered through a filter paper. The concentration of polyphenol and flavonoids in oak wooden chip extracts were determined as $1.07 \mathrm{mg} / \mathrm{g}$ and $192.12 \mathrm{mg} / \mathrm{g}$ respectively 
(Nam et al., 2018).

\section{Experiment Design and Management}

Ninety, day-old (Ross 308) male broilers with the initial body of $44.9 \pm 0.2($ mean \pm SEM) were allotted to one of three treatments having 6 replicate pens (five broilers per pen) in a completely randomized design. Similar initial body weight and weight distribution were maintained across the replicate cages. The treatments were 1) control (CON: fresh clean water without any supplementations), 2) low dose (LD: $\mathrm{CON}+1.56 \%$ EWC), and 3) high dose (HD: $\mathrm{CON}+12.5 \%$ EWC). The study lasted for 21 days.

Pen basis daily water intake was measured using the calibrated water dispenser in the individual nipple drinker units. Body weights and feed intake were measured on each week for 3 weeks. Daily weight gain, daily feed intake and feed conversion ratio were calculated based on weekly body weights and feed intake on each pen.

\section{Collection of the Samples}

At the end of experiment (day 21), sample collection was conducted to collect viscera organs and ileal tissue samples. One broiler that closer to the mean body weight was selected from each replicate pen and weighted. Broiler was euthanized via cervical dislocation and sacrificed prior to the collection of samples. Afterward, ileal from the gastrointestinal tract was separated at the points of Meckel's diverticulum and ileocecal junction. A $3 \mathrm{~cm}$ segment of distal ileal was removed and cleaned with phosphate-buffered saline (PBS) solution. Collected samples were immediately stored in the plastic containers that contained $10 \%$ of neutral buffered formaldehyde (Sigma Chemical Co., St. Louis, MO) for the fixation prior to the mucosa architecture analysis. Thereafter, liver, spleen and pancreas were removed and trimmed the excess fat depositions on each organ. Organ weights were recorded and calculated the percentage of organ weights relative to live body weight of the respective broiler.

\section{Ileal Intestinal Architecture}

Ileal tissue samples were processed following dehydration, embedding, staining and mounting on the glass according to the Pelicano et al. (2005). Thereafter, well positioned 10 villi and associated 10 crypts were selected for take villus height, villus width, crypt depth and mucosa thickness measurements using NIS-Elements viewer software (Version: 4.20; NIS Elements, Nikon, USA) with the aid of calibrated eyepiece of inverted microscope (eclipse TE2000, Nikon Instrument Inc., Melville, NY 11747-3064, USA).

\section{Statistical Analyses}

Completely randomized design was used for analyzed the data in general linear model (GLM) procedure of one-way ANOVA of SPSS software (version 24, Armonk, NY: IBM Corp.). Pen was used as the experiment unit for growth performance and water intake data while individual selected broiler was used as the experiment units for the intestinal ileal architecture and viscera organ weights analysis. Statistical significance was accepted at $P<0.05$. Turkey multiple range test between means were made when a significant treatment effect was observed.

\section{RESULTS}

Growth performance and water intake of broilers fed with three different EWC are shown in the Table 2. Broilers in the $\mathrm{LD}$ and $\mathrm{HD}$ groups showed higher $(P<0.05)$ ADWI compared to those in the CON group on day 7. Given broilers LD and HD showed similar $(P>0.05)$ ADG, ADFI and FCR compared to those in the CON from hatch to 21 days.

Ileal intestinal architecture of broilers fed with different watery treatments are shown in the Table 3 . Broilers consumed HD showed higher $(P<0.05)$ crypt depth presenting those drunk LD and CON on day 21. Therefore, broilers in HD had lower $(P<0.05)$ villus height:crypt depth ratio compared to broilers received $\mathrm{CON}$ on day 21 . No difference $(P>0.05)$ was observed in ileal villus height, villus width and total mucosa thickness of broilers fed 3 different watery treatments on day 21 .

Relative weights of the liver, spleen and pancreas did not affect $(P>0.05)$ by the EWC treatments on day 21 (Table 4).

\section{DISCUSSION}

Previous studies demonstrated that broilers fed a diet su- 
Table 2. Effect of extractions from wooden chips on growth performance of broiler for day 21

\begin{tabular}{|c|c|c|c|c|c|c|}
\hline & Item & $\mathrm{CON}^{1}$ & $\mathrm{LD}^{2}$ & $\mathrm{HD}^{3}$ & SEM & $P$-value \\
\hline \multirow{4}{*}{$\begin{array}{l}\mathrm{ADG}^{4} \\
\text { (g/day) }\end{array}$} & Day 7 & 19.67 & 19.46 & 19.50 & 0.30 & 0.962 \\
\hline & Day 14 & 54.94 & 53.02 & 52.57 & 0.62 & 0.268 \\
\hline & Day 21 & 74.98 & 70.15 & 74.88 & 1.38 & 0.280 \\
\hline & Day $0 \sim 21$ & 49.86 & 47.55 & 48.98 & 0.65 & 0.359 \\
\hline \multirow{4}{*}{$\begin{array}{l}\mathrm{ADFI}^{5} \\
(\mathrm{~g} / \text { day })\end{array}$} & Day 7 & 27.68 & 28.61 & 27.92 & 0.31 & 0.498 \\
\hline & Day 14 & 65.55 & 63.60 & 62.03 & 2.66 & 0.450 \\
\hline & Day 21 & 106.39 & 100.42 & 105.39 & 1.57 & 0.263 \\
\hline & Day $0 \sim 21$ & 66.54 & 64.21 & 65.11 & 0.76 & 0.480 \\
\hline \multirow{4}{*}{$\begin{array}{l}\mathrm{FCR}^{6} \\
(\mathrm{~g} / \mathrm{g})\end{array}$} & Day 7 & 1.41 & 1.47 & 1.44 & 0.02 & 0.624 \\
\hline & Day 14 & 1.20 & 1.20 & 1.18 & 0.01 & 0.823 \\
\hline & Day 21 & 1.42 & 1.45 & 1.40 & 0.02 & 0.673 \\
\hline & Day $0 \sim 21$ & 1.34 & 1.37 & 1.34 & 0.01 & 0.662 \\
\hline \multirow{4}{*}{$\begin{array}{c}\mathrm{ADWI}^{7} \\
(\mathrm{~mL} / \text { day })\end{array}$} & Day 7 & $72.95^{\mathrm{a}}$ & $101.57^{b}$ & $92.55^{\mathrm{b}}$ & 4.17 & 0.007 \\
\hline & Day 14 & 80.24 & 85.81 & 79.83 & 2.58 & 0.602 \\
\hline & Day 21 & 131.43 & 143.20 & 135.50 & 3.82 & 0.469 \\
\hline & Day $0 \sim 21$ & 94.87 & 110.19 & 102.63 & 2.77 & 0.069 \\
\hline
\end{tabular}

${ }^{1}$ Fresh clean water with no supplementation.

$21.56 \%$ extractions of wooden chips incorporated water.

$312.5 \%$ extractions of wooden chips incorporated water.

4 Average daily gain.

5 Average daily feed intake.

${ }^{6}$ Feed conversion ratio.

7 Average daily water intake.

Table 3. Effect of extractions from wooden chips on ileal intestinal architecture of broiler on day 21

\begin{tabular}{cccccc}
\hline \hline Item & $\mathrm{CON}^{1}$ & $\mathrm{LD}^{2}$ & $\mathrm{HD}^{3}$ & SEM & $P$-value \\
\hline Villus height (V) & 668.62 & 646.75 & 626.02 & 18.05 & 0.656 \\
Crypt depth (C) & $54.74^{\mathrm{a}}$ & $54.05^{\mathrm{a}}$ & $77.30^{\mathrm{b}}$ & 3.96 & 0.013 \\
V:C ratio & $14.09^{\mathrm{b}}$ & $12.68^{\mathrm{ab}}$ & $8.50^{\mathrm{a}}$ & 0.89 & 4.53 \\
Villus width & 60.52 & 73.51 & 63.60 & 31.93 & 0.501 \\
Total mucosa thickness & 906.23 & 948.47 & 793.33 & 0.119 \\
\hline
\end{tabular}

${ }^{1}$ Fresh clean water with no supplementation.

$21.56 \%$ extractions of wooden chips incorporated water.

$312.5 \%$ extractions of wooden chips incorporated water.

pplemented with EWC improved their growth and relevant intestinal functions including its morphology, digestibility and absorption in starter and grower phases (Zhu, 2013; Rattanawut and Yamauchi, 2015). Abovementioned studies regarding EWC had mainly used it as an acidifying and antioxidant agents by reasons of present of organic acids and phenolic 
Table 4. Effect of extractions from wooden chips on viscera organ weights of broiler on day 21

\begin{tabular}{cccccc}
\hline \hline Item (\%) & $\mathrm{CON}^{1}$ & $\mathrm{LD}^{2}$ & $\mathrm{HD}^{3}$ & $\mathrm{SEM}$ & $P$-value \\
\hline Liver & 2.16 & 2.24 & 2.06 & 0.05 & 0.358 \\
Spleen & 0.08 & 0.07 & 0.08 & 0.01 & 0.686 \\
Pancreas & 0.26 & 0.24 & 0.26 & 0.01 & 0.280 \\
\hline
\end{tabular}

${ }^{1}$ Fresh clean water with no supplementation.

$21.56 \%$ extractions of wooden chips incorporated water.

$312.5 \%$ extractions of wooden chips incorporated water.

compounds, respectively (Watarai and Tana, 2005; Rattanawut and Yamauchi, 2015). Organic acids maintain the low $\mathrm{pH}$ of gastric contents that helps to suppress pathogenic microorganism and to increase protein digestion in broilers (Abdo, 2004; Wolfenden et al., 2007). Wang et al. (2008) mentioned that presence of phenolic compounds helps to reduce substrates that increase oxidative stress in Hubbard and Shiqizha broilers on day 21. However, there were few studies investigated that drinking water added EWC on growth performance and intestinal ileal architecture of broilers in starter phase (Yamauchi et al., 2014). Interestingly, drinking water acidification using organic acid is another implementation in broiler industry used for improving growth performance (Aclkgoz et al., 2011). Therefore, current study was designed to investigate the effect of organic acids and phenolic compounds in EWC on broilers growth performance, ileal intestinal architecture and viscera organ weights.

Current study observed that broilers in in LD and HD increased water intake on day 7. Couple of studies of James and Wheeler (1949) and Smith et al. (2000) mentioned that the potassium in feed or drinking water increased the water intake in broilers. Although we were not in the position to analyze potassium content in EWC, the studies of Zulkarami et al. (2011) and Pari (2016) reported that EWC contained high concentration of potassium. Therefore, the results of our current study expressed that higher water intake could be due to reasonable amount of potassium in EWC.

In the current study, watery treatments did not significantly alter growth performance from hatch to day 21. Recent research outcome from Yamauchi et al. (2014) demonstrated that Sanuki Cochin fed 500 and 1,000 times diluted EWC had similar growth rate compared to those had clean fresh water. In addition, study of Aclkgoz et al. (2011) found no difference between broilers had water added formic acid $(\mathrm{pH}$ 4.5) and those had water without formic acid ( $\mathrm{pH}$ 7.4). In agreement to the findings, Watkins et al. (2004) concluded that water acidification using organic acids did not affect the growth performance of broilers in any stage. This could be due to high concentration of wooden chip extracts components (organic acids and phenols) may cause toxicity to broilers rather than acidifying water (Philipsen, 2006; Yamauchi et al., 2014).

In the aspect of ileal intestinal architecture of current study, there were higher crypt depth and low villus height to crypt depth ratio obtained by broilers accessed HD compared to those had CON. This result could be due to high turnover in enterocytes of broilers had HD (Savage et al., 1997; Demir et al., 2003). However, presumably broilers had HD in the current study was able to maintain their villus height without any adverse consequences compared to broilers had LD and CON. Similarly, Samanya and Yamauchi (2001) obtained that broilers (White Leghorn) fed a diet with EWC up to 5\% did not alter the ileal villus heights on day 28. Further, Ross broilers fed a corn-soybean based diet supplemented with $0.1 \%$ of organic acid did not provide a significant difference on ileal architecture on day 21 (Gunal et al., 2006). In the current study, water supplementation with HD showed deeper crypt depth suggesting the high demand for new tissue in gut mucosa. Interestingly, Yason et al. (1987) mentioned that the deeper crypt have been associated with the availability of toxic compound in the intestine of broiler and turkey. The investigation would be suggesting that the presence of toxic compounds in EWC rather than organic acids and phenolic compounds. Many studies (Shamoto et al., 1999; Shamoto and Yamauchi, 2000) demonstrated that the incorporation of EWC in to broiler diets improved the gut morphology by 
activation cell mitosis in the enterocytes. In this regard, Yamauchi et al. (2014) explained that the effect of organic components in EWC reduced the activity of the pathogenic microorganisms in the intestine that would be allowed improved gut health. It might be a one possible reason broilers had HD did not show impaired growth performance, although occurrence of many negative outcomes likely reduced ileal intestinal architecture indices (i.e., crypt depth and villous height/crypt depth ratio).

Broilers (Hubbard) fed organic acids compounds (i.e., 3\% of citric acid and acetic acid) in EWC also did not show the significant effect on proportional weight of liver and spleen compared to broilers fed CON on day 42 (Sa et al., 2008). In opposing, Fushmi et al. (2001) suggested that dietary acidification might have stimulated the glycogenesis while inhibition of glycolysis in the liver that caused enlargement of hepatic tissues in rats. In contrast with current study, broilers fed $3 \%$ of citric acid and acetic acid diets showed higher pancreas weight compared to broilers fed control diet on day 42 (Sa et al., 2008). Gauthier (2002) and Jang et al. (2004) explained that organic acids could be a cause of hyper activation of pancreatic enzyme secretion that in turn enlargement of the pancreas in broilers.

In conclusion, broilers fed HD had in reduction of villus height:crypt depth ratio without impairing growth performance and viscera organs weights for the experimental period. However, we found that no significant difference of all measured factors between LD and $\mathrm{CON}$ in the current study.

\section{ACKNOWLEDGEMENT}

This paper was financially supported by the research fund of Chungnam National University.

\section{REFERENCES}

Abdo MAZ, Zeinb A 2004 Efficacy of acetic acid in improving the utilization of low protein-low energy broiler diets. Egyptian Poult Sci 24(1):123-141.

Aclkgoz Z, Bayraktar H, Altan O 2011 Effects of formic acid administration in the drinking water on performance, in- testinal microflora and carcass contamination in male broilers under high ambient temperature. Asian-Australas $\mathrm{J}$ of Anim Sci 24(1):96-102.

Ahajji A, Diouf PN, Aloui F, Elbakali I, Perrin D, Merlin A, George B 2009 Influence of heat treatment on antioxidant properties and colour stability of beech and spruce wood and their extractives. Wood Sci Technol 43(1-2):69.

Avat F 1993 Contribution à l'étude des traitements thermiques du bois jusqu'à $300^{\circ} \mathrm{C}$ : Transformations chimiques et caractérisations physico-chimiques. Doctoral dissertation, Ecole Nationale Supérieure des Mines de Paris, Ecole Nationale Supérieure des Mines de Saint-Etienne.

Demir E, Sarica Ş, Özcan MA, Sui Mez M 2003 The use of natural feed additives as alternatives for an antibiotic growth promoter in broiler diets. Br Poult Sci 44(1): $44-45$.

Doyle ME 2001 Alternatives to antibiotic use for growth promotion in animal husbandry. Food Research Institute, Department Food Microbiology \& Toxicology, University of Wisconsin-Madison.

Duh PD, Yen GC, Yen WJ, Chang LW 2001 Antioxidant effects of water extracts from barley (Hordeum vulgare L.) prepared under different roasting temperatures. J Agric Food Chem 49(3):1455-1463.

Fushimi T, Tayama K, Fukaya M, Kitakoshi K, Nakai N, Tsukamoto Y, Sato Y 2001 Acetic acid feeding enhances glycogen repletion in liver and skeletal muscle of rats. $\mathrm{J}$ Nutr 131(7):1973-1977.

Gauthier R 2002 Intestinal health, the key to productivity: The case of organic acids. IASA XXVII convection ANECA-WPDC.

Gong L, Huang L, Zhang Y 2012 Effect of steam explosion treatment on barley bran phenolic compounds and antioxidant capacity. J Agric Food Chem 60(29): 7177-7184.

Gunal M, Yayli G, Kaya O, Karahan, N, Sulak O 2006 The effects of antibiotic growth promoter, probiotic or organic acid supplementation on performance, intestinal microflora and tissue of broilers. Int J Poult Sci 5(2):149-155.

Han KN, Kwon IK, Lohakare JD, Heo S, Chae BJ 2007 Chito-oligosaccharides as an alternative to antimicrobials in improving performance, digestibility and microbial 
ecology of the gut in weanling pigs. Asian-Australas $\mathrm{J}$ of Anim Sci 20(4):556.

Jang IS, Ko YH, Yang HY, Ha JS, Kim JY, Kim JY, Kang SY, Yoo DH, Nam DS, Kim DH, Lee CY 2004 Influence of essential oil components on growth performance and the functional activity of the pancreas and small intestine in broiler chickens. Asian-Australas J Anim Sci 17(3):394400.

James Jr EC, Wheeler RS 1949 Relation of dietary protein content to water intake, water elimination and amount of cloacal excreta produced by growing chickens. Poult Sci 28(3):465-467.

Liu RH 2007 Whole grain phytochemicals and health. J Cereal Sci 46(3):207-219.

Mateo AN, van denBerg R, Havenaar R, Bast A, Haenen GRMM 2009 Bioavailability of ferulic acid is determined by its bioaccessibility. J Cereal Sci 49(2):296-300.

Mekbungwan A, Yamauchi K, Sakaida T 2004 Intestinal villus histological alterations in piglets fed dietary charcoal powder including wood vinegar compound liquid. Anatomia, Histologia, Embryologia 33(1):11-16.

Niewold TA 2007 The nonantibiotic anti-inflammatory effect of antimicrobial growth promoters, the real mode of action? A hypothesis. Poul Sci 86(4):605-609.

Nam JB, Oh GH, Yang SM, Lee SE, Kang SG 2018 Evaluation of antioxidant activities of water extract from microwave torrefied oak wood. J Korean Wood Sci 46(2):178188.

Ogawara H 1981. Antibiotic resistance in pathogenic and producing bacteria, with special reference to beta-lactam antibiotics. Microbiol Rev 45(4):59.

Pari G 2016 Biochar technology as a go green movement in Indonesia. J Wetlands Environ Manag 2(1):84-91.

Patterson JA, Burkholder KM 2003 Application of prebiotics and probiotics in poultry production. Poult Sci 82(4):627631.

Pelicano ERL, Souza PA, Souza HBA, Figueiredo DF, Boiago MM, Carvalho SR, Bordon VF 2005 Intestinal mucosa development in broiler chickens fed natural growth promoters. Braz J Poultry Sci 7(4):221-229.

Philipsen IPLJ 2006 Acidifying drinking water supports performance. World Poult 22(5):20-21.
Rattanawut J, Yamauchi K 2015 Growth performance, carcass traits and histological changes in the intestinal villi of male broiler chickens fed dietary silicic acid powder containing bamboo vinegar liquid. J Anim Feed Sci 24(1).

Russell AD 1991 Mechanisms of bacterial resistance to non antibiotics: Food additives and food and pharmaceutical preservatives. J Appl Microbiol 71(3):191-201.

SA AF, El-Sanhoury MH, El-Mednay NM, Abdel-Azeem F 2008 Thyroid activity, some blood constituents, organs morphology and performance of broiler chicks fed supplemental organic acids. Int J Poult Sci 7(3):215-222.

Samanya M, Yamauchi KE 2001 Morphological changes of the intestinal villi in chickens fed the dietary charcoal powder including wood vinegar compounds. J of Poult Sci 38(4):289-301.

Savage TF, Zakrzewska EI, Andreasen JR 1997 The effects of feeding mannan oligosaccharide supplemented diets to poults on performance and the morphology of the small intestine. Poult Sci 76(1):139.

Shamoto K, Yamauchi K, Kamisoyama H 1999 Morphological alterations of the duodenal villi in chicks refed rice bran or grower mash after fasting. Jpn Poult Sci 36(1):38-46.

Shamoto K, Yamauchi K 2000 Recovery responses of chick intestinal villus morphology to different refeeding procedures. Poult Sci 79(5):718-723.

Smith A, Rose SP, Wells RG, Pirgozliev V 2000 Effect of excess dietary sodium, potassium, calcium and phosphorus on excreta moisture of laying hens. Br Poult Sci 41(5): 598-607.

Wang ML, Suo X, Gu JH, Zhang WW, Fang Q, Wang X 2008 Influence of grape seed proanthocyanidin extract in broiler chickens: Effect on chicken coccidiosis and antioxidant status. Poult Sci 87(11):2273-2280.

Watarai S, Tana S, 2005 Eliminating the carriage of Salmonella enterica serovar Enteritidis in domestic fowls by feeding activated charcoal from bark containing wood vinegar liquid (Nekka-rich). Poult Sci 84(4):515-521.

Watkins S, Cornelison J, Tillery C, Wilson M, Hubbard R 2004 Effects of water acidification on broiler performance. Avian Advice 6(2).

Wolfenden AD, Vicente JL, Higgins JP, Andreatti Filho RL, Higgins SE, Hargis BM, Tellez G 2007 Effect of organic 
acids and probiotics on Salmonella enteritidis infection in broiler chickens. Int J Poult Sci 6(6):403-405.

Yamauchi K, Kamisoyama H, Isshiki Y 1996 Effects of fasting and refeeding on structures of the intestinal villi and epithelial cells in White Leghorn hens. Br Poult Sci 37(5):909-921.

Yamauchi K, Manabe N, Matsumoto Y, Yamauchi KE 2014 Exterminating effect of wood vinegar to red mites and its safety to chickens. J Poult Sci 51(3):327-332.

Yason CV, Summers BA, Schat KA 1987 Pathogenesis of rotavirus infection in various age groups of chickens and turkeys: Pathology. Am J Vet Res 48(6):927-938.

Zhu YZ 2013 Detoxification effects of wood vinegar on afiatoxin B1 in broiler chicken. J Anim Vet Adv 12(14): 1256-1259.

Zulkarami B, Ashrafuzzaman M, Husni MO, Ismail MR 2011 Effect of pyroligneous acid on growth, yield and quality improvement of rockmelon in soilless culture. Aust J Crop Sci 5(12):1508.

Received Jun. 5, 2018, Revised Jul. 3, 2018, Accepted Jul. 4, 2018 